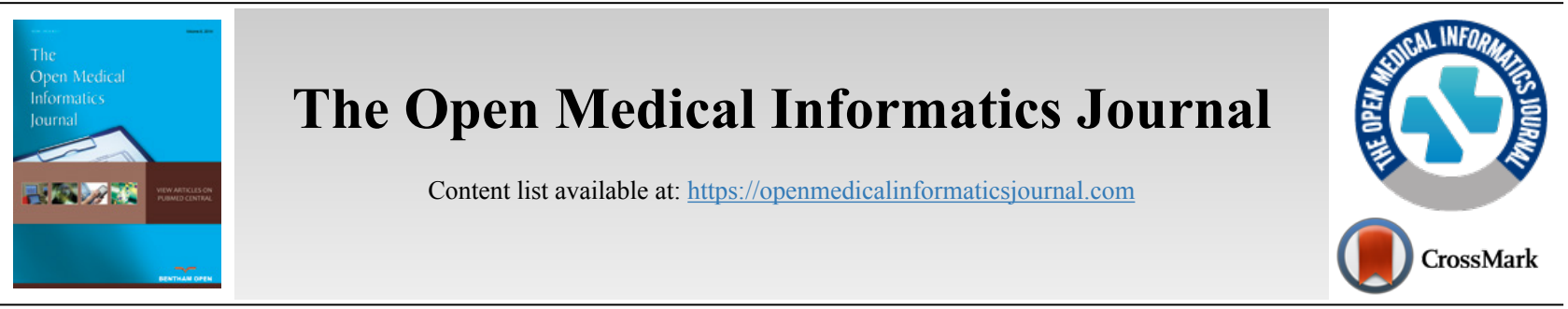

\title{
CORRIGENDUM
}

\section{Developing a Dashboard Software for the ICUs and Studying its Impact on Reducing the Ventilator-Associated Pneumonia}

Mohammad Fathi ${ }^{1}$, Hamid Moghaddasi, ${ }^{*}$, , Azamossadat Hosseini ${ }^{3}$ and Monir Ebrahimi Aghdam ${ }^{4}$

${ }^{1}$ Anesthesiology Department, Faculty of Medicine, Shahid Behashti University of Medical Sciences, Tehran, Iran

${ }^{2}$ Associate Professor of Health Information Management \& Medical Informatics, Department of Health Information Technology and Management, Faculty of Paramedical Sciences, Shahid Beheshti University of Medical Sciences, Tehran, Iran

${ }^{3}$ Department of Health Information Technology and Management, Faculty of Paramedical Sciences, Shahid Beheshti University of Medical Sciences, Tehran, Iran

${ }^{4}$ Student of Medical Informatics, Faculty of Paramedical Sciences, Shahid Beheshti University of Medical Sciences Tehran, Iran

Developing a Dashboard Software for the ICUs and Studying its Impact on Reducing the Ventilator-Associated Pneumonia

The Open Medical Informatics Journal, 2018, 12: 42-50

\section{Correction:}

The Type of the article was changed to Research article from Review.

(C) 2019 Fathi et al.

This is an open access article distributed under the terms of the Creative Commons Attribution 4.0 International Public License (CC-BY 4.0), a copy of which is available at: https://creativecommons.org/licenses/by/4.0/legalcode. This license permits unrestricted use, distribution, and reproduction in any medium, provided the original author and source are credited. 